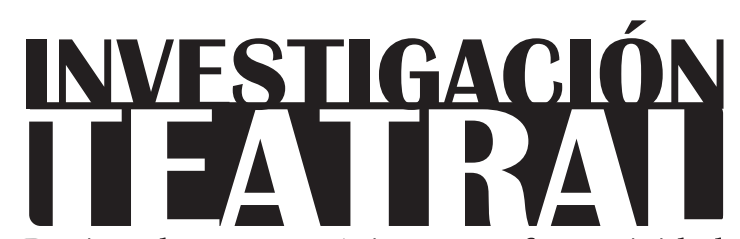

Revista de artes escénicas y performatividad

Vol. 9, Núm. 13

abril-septiembre 2018

Segunda época

ISSN impreso: 1665-8728

ISSN electrónico: 2594-0953

Universidad Veracruzana

\title{
El teatro como crítica institucional
}

\author{
Óscar Cornago*
}

\author{
* Consejo Superior de Investigaciones Científicas, \\ Madrid, España. \\ e-mail: oscarcornago@yahoo.com
}

Recibido: 20 de julio de 2017

Aceptado: 12 de diciembre de 2017 


\title{
El teatro como crítica institucional
}

\section{Resumen}

Este artículo discute el sentido de las prácticas teatrales en relación a los contextos institucionales en los que se desarrollan. Para ello, se analiza la dimensión institucional del teatro en relación a las artes visuales. La reacción ante repertorios de formas y usos ya instituidos ha abierto un ámbito de confluencias entre las prácticas performativas y las visuales. Con el fin de trazar diversos recorridos dentro de este panorama, se estudian proyectos de creación de España, Alemania, México, Líbano y Brasil, algunos de ellos pertenecientes a la programación de la in Mostra Internacional de Teatro de São Paulo del 2017. Estas obras intervienen sobre los marcos ya legitimados de actuación, con el fin de cuestionar la construcción institucional del teatro, abriendo nuevos posibilidades de creación y reflexión en relación al espacio de la representación.

Palabras clave: institución, legitimación, lugares de actuación, teoría escénica, teatro contextual, Brasil.

\section{Theatre as Institutional Critique}

\begin{abstract}
This article discusses the meaning of theatrical practices in relation to the institutional contexts in which they develop. Attention is paid to the institutional dimension of theater in relation to the visual arts. The reaction to established repertoires has opened a confluence between performative and visual practices. In order to trace different routes within this panorama, projects from Spain, Germany, Mexico, Lebanon and Brazil are studied, some of them belonging to the programming of the III International Theater Festival of São Paulo (2017). These plays intervene in the legitimated frameworks around performance, with the purpose of questioning the institutional construction of theater while opening possibilities of new territories of creation and critique within the spaces of representation.
\end{abstract}

Keywords: Institution, Legitimation, Places of Acting, Performing Theory, Contextual Theatre, Brazil. 


\section{El teatro como crítica institucional}

\section{¿Instituciones de aficionados?}

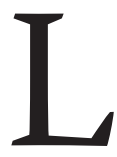
a figura del aficionado desafía la lógica de la institución. En tanto que "cosa establecida o fundada", según la definición de "institución" que ofrece el diccionario de la RAE, el único lugar que puede ocupar un aficionado es como cliente o usuario, en todo caso, el de un personaje de paso por un espacio cuyo capital simbólico se apoya en lo ya instituido, pero cuyo potencial activo descansa, sin embargo, en su capacidad instituyente, atendiendo a un presente en movimiento. El aficionado pone en riesgo la legitimidad de la institución, pero, al mismo tiempo, la institución necesita de él para luchar contra la endogamia implícita en una dinámica de profesionalización.

El interés que la figura del aficionado despierta en el campo de las artes es una respuesta a la reacción, a la institucionalización de las prácticas artísticas en ámbitos perfectamente definidos. No hay que entender dicho interés como un ataque al conocimiento, al saber hacer o a la necesidad de estudio, sino al peligro de aislamiento y autonomía inherente a los procesos de especialización. El aficionado apela a un territorio humano que se alimenta del no saber y la pasión por el saber, el gusto por seguir aprendiendo y reinventándose uno mismo en relación a un horizonte cognoscitivo, más allá de rentabilidades de otro orden. La falta de credibilidad en las instituciones -incluyendo las del arte y el teatro- que caracteriza a los sistemas políticos contemporáneos, tiene sus raíces en la distancia con la que desde afuera se perciben esas complejas construcciones públicas que deberían estar al servicio de todos, incluidos, por supuesto, los aficionados. 
En Amateur $^{1}$ (2016) el artista, actor, director y dramaturgo es un intérprete de piano que desde el inicio se presenta como aficionado. La obra dura lo que dura la partitura elegida para la ocasión. En la primera edición fue una pieza del compositor renacentista Orlando Gibbons, en la segunda las Variaciones Goldberg de Johann Sebastian Bach. Al mismo tiempo que se interpreta la pieza, se proyecta un texto del ejecutante escrito en primera persona, dónde éste explica al público lo que está tocando y le habla de su relación con la música, especialmente el piano, tema que, a su vez, lo lleva a tratar muchas otras cuestiones. En principio parece que el único elemento que permite identificar a la obra como un evento teatral - y no solamente un concierto - es el texto proyectado en el escenario, pero hay otro factor que debemos tener en cuenta y que podría pasar fácilmente desapercibido: el marco cultural, tipo de programación o espacio institucional que acoge a la propuesta —en este caso, ámbitos dedicados a las artes escénicas- - La obra podría hacerse perfectamente en un auditorio de música clásica, incluso con la proyección del texto, pero el efecto teatral (o antiteatral) ya no sería el mismo.

En caso de interpretarse en un auditorio, la obra pasaría a ser lo que literalmente es: un concierto de piano al que se añade una mirada autorreflexiva. Dicha mirada, sobre la que se construye el efecto teatral que caracteriza a la obra, opera como un tercer ojo que impide que nos olvidemos del lugar en el que nos encontramos y lo que estamos haciendo allí. La teatralización del momento nos hace percibir lo que está pasando en relación a una serie de contingencias externas al propio concierto, pero que lo determinan. Esos elementos, que podemos denominar contextuales, tienden a pasar inadvertidos: cuestiones como la presencia silenciosa del público protegido por la oscuridad del patio de butacas, la relación del autor (gracias a la reciprocidad de los espectadores) con lo que está pasando en el escenario, así como el tipo de estímulo que lo llevó a aceptar dicho trabajo; finalmente, lo que se cobra por asistir al espectáculo y lo que llevó al público a acudir al teatro la noche de la función. En "condiciones normales de recepción”, el público abstraería todos estos elementos, los pondría entre paréntesis para sumergirse en el viaje interior al que invita la partitura. Pero nombrarlos o señalarlos a través del texto, hace que la percepción de la obra varíe sustancialmente y que esas variaciones no sean ya sólo musicales, sino también escénicas, dependientes del lugar y el contexto en el que se interpretan.

1 Amateur es un proyecto que se crea en 2016 como parte de un programa de residencias del espacio Nyamnyam de Barcelona. Hasta el momento ha tenido dos ediciones: Gibbons Amateur (2016) y Goldberg Amateur (2017). Se ha realizado en Teatro Pradillo (Madrid), Antic Teatre (Barcelona), el Festival TNT (Terrassa) y el ciclo Teatro Raro de CiudaDistrito (Madrid). Puede consultarse más documentación y material gráfico en la página del artista: http://www.fuga.es/amateur/. 
Pero, ¿a qué llamaríamos “condiciones normales de recepción”? Las condiciones normales son aquellas marcadas por una cierta normativa o convención cultural acerca de cómo se debe hacer público un tipo determinado de obra y cómo se debe recibir. Dichas condiciones, convertidas en convenciones aceptadas por una sociedad, son las que invisibilizan los marcos de ocurrencia. En un concierto de piano, por ejemplo, tales condiciones están ligadas a un auditorio musical, cuyo marco cultural es justamente el horizonte del que se distancia Amateur. La escena le proporciona el medio para esta distanciación crítica. El ejercicio de distanciamiento, a su vez, es lo que en este caso teatraliza la obra, aunque en muchos casos - como en la interpretación de Amateur en el Centro Cultural Las Rosas de Madrid en 2017- sería posible que la diferencia radique únicamente en el uso que se hace del espacio.

Ahora bien, el desplazamiento no opera únicamente en relación al horizonte musical, sino que afecta también al contexto teatral. Se hace un uso desviado del espacio teatral, pues se le utiliza para ofrecer un concierto de piano que es - como se advierte en el textoprecisamente lo que se quiere evitar: dar un concierto de piano más. Para ello se recurre a la teatralización de la interpretación del pianista. Al teatralizarla, es decir, al hacer consciente al público de una serie de circunstancias personales y no personales que explican la historia del intérprete con la música (y más concretamente con la partitura que está interpretando), se crea otro tipo de situación pública que permite tomar distancia con respecto a los modos habituales de hacer y consumir la música antigua a través de esos eventos que se denominan "conciertos de música clásica", caracterizados por una serie de convenciones, actitudes, juicios y prejuicios.

Se trata de rasgos que forman parte de lo que podríamos llamar "la institución musical", la cual es tomada como objeto de la crítica planteada por Amateur. Ese tercer ojo, que se construye a través de un ejercicio de reflexión en voz alta, no sólo hace visible al intérprete mientras toca lo que aparentemente se le iría pasando por la cabeza, sino que señala también al público que se encuentra en silencio del otro lado del escenario, por más que en el texto se le provoque a adoptar actitudes diferentes. Pero alude, por otra parte, a los códigos culturales de la misma institución que acoge la obra: el tipo de espacio teatral en el que acontece la función, por ejemplo, haciendo referencias a lo que pasó en ese mismo espacio el día anterior, etcétera. Se muestra todo un ámbito en torno al acontecimiento, con el fin de reconsiderar el hecho singular de estar asistiendo a un concierto de música antigua sacado de los formatos que normalmente lo tendrían capturado.

La obra comienza con la entrada del intérprete en escena, inevitablemente también director y actor de la puesta. El piano esta frente al público desde antes, iluminado por una luz cenital. El músico se sienta de espaldas a la audiencia, se prepara un momento y comienza a tocar. Si por un lado se va a dirigir a los espectadores, por el otro parece olvidarse 
de su presencia, como si no quisiera saber nada de ellos, aunque tampoco le incomodan (algo que será comentado explícitamente). Poco después de iniciado el concierto, empiezan a aparecer los textos sobre el fondo del escenario. Se puntualiza que el intérprete no es profesional sino un aficionado - aunque una gran parte del público posiblemente no notaría la diferencia- y que hace eso porque le gusta, incluso se pide una disculpa por los posibles errores de interpretación. Dicho conflicto entre el significado de ser amateur o profesional será el eje sobre el que girarán gran parte de las reflexiones plasmadas. Lo profesional queda relacionado con el ámbito del trabajo, el deber, una rentabilidad clara, pero por ello también con las propias expectativas y el miedo a no estar a la altura de las mismas. El amateurismo, en cambio, se piensa en relación con el gusto por hacer las cosas desde una cierta gratuidad, incluso si no salen tan bien, con la posibilidad del error, la experiencia interior del aprendizaje y la satisfacción de notar ciertos progresos, aun renunciando a buscar la perfección. Se habla del tema de la democratización de los placeres, planteándole en algún momento al espectador: ¿te imaginas si el porno estuviera reservado únicamente a los profesionales?

La reflexión del texto proyectado no alude explícitamente al mundo escénico, pero es obviamente en el espacio y la institución teatrales donde repercute el uso desviado que se hace de la escena. Desde un punto de vista práctico - donde "práctica" se referiría no a la interpretación musical, sino a la actuación a través de la construcción subjetiva del texto-, es el teatro el medio donde resuenan dichas críticas. No es casualidad que sea ésta la perspectiva desde la que se sitúa la obra dentro del ciclo Teatro Raro ${ }^{2}$ de los distritos de Madrid:

Todo el mundo entiende esto. Lo que no encaja. Lo imprevisto. Lo inusual. Lo que no ocurre en un teatro. Lo que ocurre en un teatro pero no ocurre como siempre. Como se espera. Creadores que transitan ajenos a los límites y convenciones de las artes escénicas. Que son muchos. Los creadores, los límites y las convenciones. ${ }^{3}$

2 Teatro Raro es una de las líneas de programación cultural del Ayuntamiento de Madrid (https://ciudadistrito.es/) a raíz del relevo político de 2015, cuando el grupo conservador Partido Popular fue sustituido por el recién formado "Ahora Madrid" (integrado por distintas formaciones y agentes culturales de izquierdas). No es casualidad que dicho relevo, a nivel nacional formado también por partidos de derechas, valorara el que muchos de sus integrantes no sean políticos profesionales y apelara a la necesidad de reinventar los usos de la política.

${ }^{3}$ Extraído de la presentación del ciclo Teatro Raro en la programación de actividades culturales del Ayuntamiento de Madrid-CiudaDistrito: https://ciudadistrito.es/dejate-sorprender-con-el-teatro-raro/. 


\section{El arte como crítica institucional}

La disfuncionalidad del objeto artístico, por la cual este último escapa a la lógica de la producción material y su rentabilidad, queda en entredicho, hace que en alguna medida todo arte tenga algo de crítica hacia las instituciones que lo producen, lo explican y lo conservan, mostrando a fin de cuentas la rentabilidad de lo aparentemente no rentable. Junto a la lógica de la producción material conviven otras lógicas culturales, que, atendiendo a otras reglas, hacen que el arte pueda convertirse en uno de los campos de especulación preferidos por el capitalismo. Las instituciones no sólo validan un determinado enunciado histórico acerca del arte, señalando ciertos espacios artísticos, sino que también sancionan los usos adecuados del arte y educan al público en las formas de entenderlo y apreciarlo correctamente.

El arte no está conformado solamente por las obras producidas, sino que implica a un complejo sistema cultural sostenido por instituciones que lo sitúan en un lugar determinado. La crítica de estos ámbitos de legitimación artística, identificados con instituciones como los museos, teatros, centros de educación y de creación, así como con las universidades y otros ámbitos de formación, es parte de la propia historia y teoría del arte. Ya en los años treinta John Dewey, que dedicó tantas páginas a entender la política y la educación de forma menos normativa, abre su libro El arte como experiencia cuestionando la validez de los museos como marcos de exhibición de las obras, aludiendo a la economía de aislamiento y acumulación que sostienen estas instituciones:

Cuando un producto de arte alcanza una categoría clásica se aísla de algún modo de las condiciones humanas de las cuales obtuvo su existencia, y de las consecuencias humanas que engendra en la experiencia efectiva. [...] Cuando los objetos artísticos se separan tanto de las condiciones que los originan, como de su operación en la experiencia, se levanta un muro a su alrededor que vuelve opaca su significación general, de la cual trata la teoría estética (3).

No es difícil rastrear en Amateur los argumentos de Dewey en relación con la condición canónica de ciertas obras y contra el efecto de embalsamamiento que conlleva la propia institución. Arte, institución, mercado, producto, experiencia... el conflicto no es nuevo. En los años cincuenta y sesenta, con el crecimiento de la economía de consumo, la sociedad de masas y las industrias culturales, se extiende lo que historiadores como Benjamin Buchloh - siguiendo la estela de los conceptualismos-denominaron crítica institucional del arte ("El arte conceptual"). Más recientemente, a partir de los noventa y como respuesta a los efectos de la economía neoliberal en el campo cultural, esta línea 
crítica fue retomada por creadores y teóricos del arte (véase la plataforma de investigación en artes denominada Transform). ${ }^{4}$

El recorrido de la escultora brasileña Lygia Clark resulta significativo a este respecto. Su evolución en busca de nuevas formas de situar su obra en el espacio público, de ponerla en relación con la gente y colocarse ella misma en relación al mundo a través de su trabajo, supone una constante labor de reflexión sobre los límites y funcionamiento de la institución artística. Desde el movimiento neoconcreto hasta la etapa de los objetos relacionales - utilizados en las sesiones individuales de terapia que la artista realizó en su propia casa hacia el final de su carrera-, pasando por Bichos y sus trabajos con materiales blandos y ropas, Clark no dejó nunca de explorar formas distintas de rehacer la experiencia artística junto con el público. La teatralización del arte, que durante las vanguardias históricas se construye como una reinvención y un juego del artista con su identidad, en la segunda mitad de siglo estará motivada sobre todo por el deseo de atravesar los lugares oficiales del arte, haciendo visibles las condiciones de la producción artística con el fin de transformar sus formas de uso. Se trata de una dinámica de desplazamientos cuyo fin no es la llegada a un determinado punto, sino mantenerse en constante movimiento para evitar fijar el sentido de la obra y la experiencia a la que da lugar, porque como explicaba Clark:

En el preciso momento en que el artista digiere el objeto, es digerido por la sociedad que ya le encuentra un título y una ocupación burocrática: será así el ingeniero de los pasatiempos del futuro, actividad que en nada afecta el equilibrio de las estructuras sociales (cit. en Roznik parr. 4).

Esta podría ser otra cara de la argumentación de Dewey sobre el arte como objeto de museo. Si el filósofo se refería a esto ya en los años treinta desde el punto de vista de la teoría estética, es ahora una artista quien, unas décadas más tarde, expone el mismo problema desde el punto de vista de la experiencia del creador y su lugar dentro de las lógicas de la producción y del mercado. En definitiva, la finalidad de Rubén Ramos al tratar de sacar a la música antigua - e indirectamente al propio teatro- de los marcos de consumo que imponen unas normas determinadas, coincide con aquella intención. Las respectivas posiciones del filósofo, la artista conceptual y el creador escénico, coincidentes en cierto modo a pesar de la distancia que las separa, servirían en todo caso para dar respuesta a

4 Transform, ed. Producción cultural y prácticas instituyentes. Líneas de ruptura en la crítica institucional. Madrid: Traficantes de sueños, 2008. También en transform.eicpc.net. http://transform.eipcp.net/transversal/0808. Consultado el 20 de julio de 2017. 
una pregunta que, más recientemente, plantea Brian Holmes al comienzo de su ensayo sobre las nuevas formas de la crítica institucional:

¿Cuál es la lógica, la necesidad o el deseo que impulsa a cada vez más artistas a trabajar fuera de los límites de su propia disciplina, definida por nociones de reflexividad libre y estética pura, materializada en el circuito galería-revista-museo-colección y acechada por la memoria de la pintura y la escultura como géneros normativos? (203)

La crítica institucional no se ha desarrollado con suficiente fuerza en el ámbito teatral, a pesar de que las instituciones teatrales ocupan un importante espacio público y simbólico. Éstas están a menudo representadas por los teatros nacionales, esos edificios que constituyen referencias históricas importantes. Si las artes en general exigen un grado de institucionalidad para conformarse públicamente, en el caso del teatro la coraza institucional es aún mayor, debido a la función que éste ha tenido en muchos momentos de la historia en relación no sólo al desarrollo de los géneros literarios (en épocas en las que no había imprenta), sino también a la construcción de identidades nacionales y debates culturales que surgieron a partir del siglo XVIII en adelante.

La finalidad de este artículo es echar un vistazo al medio escénico, enfocándolo a través de esta inquietud en torno a la dimensión institucional que configura un espacio de creación artística y discutiendo el problema. Para ello se señalará comparativamente la relación entre el teatro y el museo como espacios simbólicos correspondientes a dos distintos tipos de instituciones artísticas que, sin embargo, han buscado en los últimos años espacios de confluencia. En segundo lugar, se considerarán algunos proyectos creativos que cuestionan los límites de la institución teatral, invitando a repensar su lugar como espacio práctico de discusión y acción pública.

La crítica institucional, a través del acontecimiento escénico, despliega una teatralidad que ya no afecta solamente a la obra sino también a la situación y el contexto donde ésta opera. La teatralidad de la obra deja así de circunscribirse a determinados lenguajes fijados por la tradición y comienza a corresponder al ejercicio de cuestionamiento de los marcos de legitimación artística que se busca desarrollar. Trasladando la pregunta de Holmes al medio escénico, quedaría formulada de este modo: ¿Cuál es la lógica, la necesidad o el deseo que impulsa a cada vez más actores y directores de teatro, coreógrafos, escenógrafos y bailarines a trabajar fuera de los límites de su propia disciplina, definida por nociones de reflexividad libre y estética pura, materializada en el circuito teatro-auditorio-centro_cultural-galería-calle y acechada por la memoria del teatro y la danza como géneros normativos?

A raíz del los años 2000, Holmes distingue una nueva etapa en las formas de crítica institucional guiada por la extra-disciplinariedad, la cual habría estado precedida por 
dos tendencias: la inter-disciplinariedad y la in-disciplinariedad. Estas últimas son fácilmente reconocibles en el medio escénico a partir de los años sesenta, por ejemplo, en la "contaminación" de lenguajes (teatro, danza, performance, video) y la disolución de sus fronteras, expresada en algunos casos a través de actitudes irreverentes - piénsese en la performance y el teatro físico- que buscaban la producción de nuevas subjetividades. Coincidiendo con otras voces críticas que han tomado como eje de sus reflexiones a las formas de producción artística — como Bojana Kunst (Artist at Work) -, Holmes insiste en que tales estrategias ya han sido actualmente identificadas, habiendo agotado entonces su capacidad crítica y quedando convertidas en productos culturales que se cierran sobre sí mismos (autorreflexividad). Es decir, la obra se conforma, en este caso, girando sobre sí misma y autoenvolviéndose, condicionada, por el marco en el que se presenta, a ser un producto artístico más.

Tal acoplamiento entre las obras y el medio cultural era calificado por Lygia Clark como ingeniería del entretenimiento. El alcance de esta clausura autorreflexiva -o, visto en positivo, la capacidad crítica que aún puedan conservar este tipo de disonancias y desplazamientos-, no es, sin embargo, algo que pueda medirse objetivamente. La pieza de Rubén Ramos citada arriba, por ejemplo, se acerca a la extradisciplinariedad en la medida en que utiliza el escenario como espacio de discusión y expresión de otro tipo de lenguaje artístico, pero no escapa al riesgo de la clausura autorreflexiva.

Más que como una etiqueta clasificatoria con una definición clara, resulta entonces preferible entender la "extradisciplinariedad" planteada por Holmes como una perspectiva metodológica. En todo caso, en este artículo adoptamos como punto de partida la necesidad expresada por dicho concepto de colocar al trabajo artístico -y más concretamente al trabajo escénico - en diálogo con otros espacios de investigación, conflictividad y conocimiento (la música en el caso de Amateur o la sanación en el caso de los objetos de Lygia Clark, por ejemplo). Es en este sentido que Holmes diferencia entre tropismo y reflexividad:

El término 'tropismo' expresa el deseo o la necesidad de girarse hacia otra cosa, hacia un campo o disciplina exteriores; mientras que la noción de reflexividad indica ahora un regreso crítico al punto de partida, un intento de transformar la disciplina inicial, acabar con su aislamiento, abrir nuevas posibilidades de expresión, análisis, cooperación y compromiso (205).

El desencuentro es la figura que voy a utilizar como gesto crítico y estético a lo largo de las siguientes páginas; no el desencuentro en sentido literal, sino ciertos umbrales de no-coincidencia entre el sitio oficial que se le confiere a una obra por el contexto al que está asignada, y el espacio estético y situación escénica que dicha obra logra producir. Se trata de un 
territorio de desplazamientos que voy a intentar mostrar con el valor de una figura estética con posibilidades críticas.

A pesar de las numerosas tendencias de teatro fuera de los teatros que vemos actualmente, como proyectos site-specific o intervenciones urbanas, los recintos artísticos convencionales (teatros, galerías, centros de arte o museos) siguen siendo los espacios que con mayor frecuencia albergan la producción artística. Éstos suponen a la vez un contexto y marco de trabajo específicos, que por lo general pasan desapercibos al haber quedado integrados y confundidos dentro de nuestro sentido común. Resulta obviamente normal que el teatro se haga en los teatros o el arte en las galerías; no obstante, dichos espacios no son meros continentes neutrales sino que se fueron configurando a través de una historia específica y determinado tipo de relaciones sociales. Cuestionar a la normalidad cultural y artística sostenida desde un horizonte institucional, permite recuperar para las prácticas de creación una cierta anormalidad que obliga a repensar su sentido en relación con su entorno.

\section{Instituciones artísticas y teatrales}

Las instituciones teatrales y las dedicadas a las artes visuales han abierto territorios de confluencia, como resultado de la creciente indefinición de los límites entre las prácticas artísticas en general y la necesidad de proyectarse hacia fuera para reactivar localmente los vínculos con las sociedades. La disolución estratégica de las fronteras no es un fin en sí mismo, sino un medio para resituar el trabajo artístico de modos distintos frente a los ámbitos públicos en los que se presenta. Es frecuente que museos y centros culturales de reciente creación, así como algunos de los ya tradicionales cuando son remodelados, prevean la convivencia entre formas de creación diversas. Artes visuales, danza, teatro, performance, intervenciones urbanas... pasan a formar parte de un paisaje común.

Sin embargo, las respectivas genealogías y casuísticas que han llegado a conformar a cada uno de estos espacios como buques insignia de los escaparates culturales de los estados, son bien distintas. La diferencia estriba esencialmente en la naturaleza de las obras artísticas que tradicionalmente han custodiado los museos, frente a la de aquellas que han custodiado los teatros; sus lógicas y necesidades diversas y sus respectivos roles como parte del patrimonio cultural. La fuerte dimensión patrimonial que tanto el teatro como el museo encierran, les confiere a ambas una tarea común: la correcta conservación, estudio y actualización de un pasado a través de las obras. Ahora bien, los modos de reactualizar dicho pasado artístico o la forma de construir y sostener tales relatos históricos situándolos en relación con un presente, difieren notablemente. 
A diferencia de lo que ocurría en las artes visuales, las instituciones escénicas (teatrales, dancísticas o musicales) han demandado siempre de algún tipo físico de interpretación para actualizar sus obras, a menudo conservadas y transmitidas como textos dramáticos en papel, coreografías o partituras musicales. En el caso de los museos, tradicionalmente se alzaba entre los objetos de arte y el público un dispositivo materializado en la arquitectura y disposición del propio museo o la galería; una mediación abstracta que implicaba una interpretación teórica pero no física.

Esto comenzó a cambiar, sin embargo, durante la segunda mitad del siglo xx, cuando el medio de las artes visuales se fue abriendo a un amplio abanico de tendencias en torno a la peformance, las artes de acción y las del cuerpo o del movimiento. Los museos se vieron obligados a introducir otro tipo de mediaciones interpretativas, como el cuerpo de los performers, los bailarines o - más recientemente - los "facilitadores", si bien, intentando conservar el estatus del resultado artístico como objeto de contemplación por parte del público.

Por otro lado, la actualización de la obra por parte del intérprete musical, actoral o coreográfico pone en juego un ámbito de posibilidades que ha sido objeto de una estricta vigilancia por parte de las instituciones. El tema de la libertad interpretativa versus la fidelidad a los textos dramáticos, partituras o condiciones históricas de representación —cuando se ha llegado a considerar que ahí radica la autenticidad de la obra y su verdadero valor artístico-, es uno de los conflictos que han definido la historia de estos medios. En las artes interpretativas, la conservación del patrimonio recae sobre unos cuerpos vivos que tradicionalmente han tenido que estar al servicio de un director, dramaturgo o coreógrafo que se responsabiliza de afinar el sentido de la interpretación. Pero a lo largo del siglo xx, los actores (incluso en el sentido más general de agentes sociales, más allá de los actores de teatro) van a cuestionar dicha relación de subordinación. La interpretación de la historia y la relación con el pasado se han adentrado, actualmente, en un terreno inestable que problematiza los relatos lineales y las lógicas causales.

Bajo cierta metáfora teatral, la historia se muestra como un escenario político que hace visibles unos nombres, acontecimientos e interpretaciones mientras deja otros en la sombra. Si tanto en los espacios artísticos como en la historia del arte se desarrolla un movimiento de desobjetualización, en los medios escénicos se implementa una tendencia paralela a la desactorización. Ni el objeto artístico ni los actores escénicos serán desechados definitivamente (al menos no ha sucedido aún), pero se ha inaugurado una dinámica de cuestionamiento en torno a los límites de la obra y la condición del actor (no sólo como mediación o continente físico, sino también como sujeto y potencia crítica de desestabilización). Y esta reflexión sobre los lugares de actuación ha implicado, desde luego, una revisión de los lugares de enunciación como espacios de legitimación. A final de cuentas, lo que se trastoca también es la posición del espectador y los modos de recepción de las 
obras - a favor de formas y ámbitos de relación más abiertos e inestables, en los que la responsabilidad de la interpretación pasa a ser compartida por todos los agentes que toman parte del evento escénico (tanto intérpretes físicos como ayudantes, técnicos, gestores y, por supuesto, el público en general)-.

De este modo, si los museos se teatralizan — no sólo en cuanto a la estética de las obras, sino, sobre todo, por la manera de actualizarlas y hacerlas públicas - recurriendo a menudo a la performance, los teatros se desteatralizan tomando distancia frente a sus ropajes y usos tradicionales para adoptar formas de teatralidad más contextuales, comparables en algunos casos a las desarrolladas recientemente en los museos. La tendencia a la abstracción espacial, compartida por teatros y museos, busca adelgazar la mediación interpretativa dando mayor protagonismo al público. Cubos blancos y espacios polivalentes tratan de crear una sensación de neutralidad, de espacio vacío, sin historia ni pasado, donde cada nueva obra puede recibirse con los mínimos condicionamientos.

Frente a esta asepsia expositiva, los proyectos de creación -como apuntaba Holmes en relación a la extradisciplinariedad- lanzan cabos hacia el mundo de afuera. A veces intentan hacer visible la historia y memoria detrás de esos espacios de exposición o representación, así como el rol esencial que los asistentes -identificados provisionalmente por un término tan abstracto como el de público- han jugado siempre en la configuración de tales dispositivos culturales. Como veremos a continuación, los teatros, a través de nuevas líneas curatoriales que han hecho posible otro tipo de proyectos de creación, hoy pueden adquirir también una dimensión expositiva. Y los espacios dedicados a las artes visuales, recíprocamente, se teatralizan dando lugar a espacios confluyentes en los cuales es posible repensar los límites y potencias de ambas instituciones.

Ahora bien, cerrar este apartado aquí podría generar falsas expectativas o no responder al estado actual de la cuestión. Es necesario observar que las inercias institucionales son fuertes: solamente en años muy recientes se ha extendido el interés por las artes escénicas en los museos como una perspectiva transversal, al tiempo que se han ido abriendo los formatos escénicos tradicionales - danza y teatro - a una diversidad de posibilidades que rebasan el marco de la escena. Es, sin embargo, en este último campo donde los recelos institucionales y el afán por conservar derechos adquiridos ofrecen mayores resistencias al proceso descrito de apertura y renuncia a lenguajes ya constituidos. El capital simbólico que reside en el cuerpo del actor y el riesgo que para las instituciones, la ortodoxia cultural y los intereses creados supone la emancipación de dichos cuerpos en relación a los textos y partituras que deben interpretar, explica el conservadurismo formal del teatro frente a otros ámbitos artísticos.

Cuando Chris Dercon tomó la dirección del teatro berlinés de la Volksbühne en 2018, los recelos no se hicieron esperar, transformados en algunos casos en movimientos de 
protestas. Que una institución que había estado dirigida por figuras históricas como Max Reinhardt, Heiner Müller y, más recientemente, Frank Castorf, pasase a quedar en manos de un prestigioso director de museos y espacios artísticos a nivel internacional (como la Tate Gallery de Londres en su última etapa) resultó cuando menos llamativo en los círculos teatrales. Una reacción comparable se vivió en Madrid a raíz del nombramiento del nuevo director de los espacios destinados al teatro dentro del complejo cultural y centro de creación artística Matadero. El proyecto de Mateo Feijóo para las Naves de Matadero generó una sonora polémica, alimentada por una carta dirigida al Ayuntamiento de Madrid - firmada por numerosos profesionales del medio teatral-, denunciando que esta ciudad "perdía un teatro" con toda la carga simbólica y demagógica que ellos veían en dicho gesto. A esto se respondió con una nueva carta - que contó, a su vez, con el apoyo de numerosos creadores del ámbito del teatro, la danza y las artes en general-, reclamando un reparto más equitativo de los recursos públicos (centrados hasta el momento en el subsidio a un sólo tipo de teatro). Los muros de la institución teatral, identificada con determinados modos de hacer y pensar el teatro, parecen no aguantar más el reto que arrojan nuevos tiempos, que impulsan un uso más diverso de los espacios públicos de creación escénica.

En Radical Museology, a través del estudio de tres museos -entre los que se cuenta el Museo Nacional y Centro de Arte "Reina Sofía", que no por casualidad en los últimos años ha sido abordado constantemente por diversos proyectos de investigación y tomado como escenario de varias obras teatrales, dancísticas y performances-, Claire Bishop analiza nuevas formas de convertir los museos en espacios verdaderamente contemporáneos. El libro puede invitarnos a trasladar la reflexión también al ámbito de las instituciones escénicas y preguntar qué es "contemporáneo" en los centros de teatro contemporáneo. Podría desarrollarse una investigación análoga que se enfoque en la transformación de algunos espacios teatrales en centros de creación abiertos a una diversidad de formas escénicas, como las citadas Naves de Matadero. Otro ejemplo podría hallarse en la gestión de Rodrigo García al frente del Teatro de Montpellier (perteneciente a la red nacional de teatros franceses), durante la cual el sitio pasó de llamarse Le Théâtre des Treize Vents - y de estar dedicado a un repertorio clásico y a un público de élite - a ser el "hTh" (Humain trop humain), asumiendo un giro radical en su programación y en la forma de pensar al teatro en relación a su entorno.

Menos traumática ha sido la relación entre la danza y el museo. Al no estar tan identificada con la palabra y el texto, aquélla ocupa un espacio simbólico y patrimonial diferente. La relación entre el museo y el ámbito expandido de la danza, articulado a partir de los años noventa en torno al concepto de coreografía, venía ya precedida - al igual que la relación museo-teatro- por el horizonte transversal abierto por la performance. La pregunta so- 
bre cómo meter en el museo a la danza (coreografía de movimientos) y qué lugar darle al cuerpo y a la acción dentro del espacio expositivo, desplegó un nuevo ámbito de reflexión cultural y artística. Tampoco dejó de implicar, nuevamente, el riesgo de provocar que tales acontecimientos quedaran reducidos a objetos de contemplación al servicio del potente marco de la galería o el museo (cuando en su concepción creativa aspiran a ser lo contrario: intentos de romper con los marcos habituales del trabajo artístico o dancístico).

Proyectos como 20 bailarines para el siglo $\mathrm{xX}$ de Boris Charmatz - también conocido como el "Museo de la danza"-, acogido en 2016 por el Museo Reina Sofía; o Una exposición coreografiada de Mathieu Copeland, que pasó por el Centro de Artes Dos de Mayo perteneciente a la Comunidad de Madrid - un espacio más joven que desde su apertura apostó por un diálogo horizontal entre prácticas y formatos artísticos distintos-, podrían ser buenos ejemplos de estos nuevos territorios contemporáneos de confluencia. Para la exposición a cargo de Copeland, que se acompañó de la publicación colectiva Coreografíar exposiciones, el comisario invitaba a nueve coreógrafos (entendiendo el concepto en su sentido más amplio) a proponer partituras de movimiento. El resultado fueron trabajos que integraron a creadores teatrales tan significativos en la escena contemporánea como Tim Etchells (director artístico de Forced Entertainment), interpretados en bucle durante los días que duró la exposición.

Las reacciones ante el riesgo de una probable musealización del lenguaje coreográfico no se han hecho esperar, a pesar de que las intenciones de estos creadores han sido justamente de ruptura ante los rígidos espacios y contextos de trabajo de la danza clásica y moderna. Véanse, por ejemplo, las preguntas que se plantea la coreógrafa Amalia Fernández en Expografía (2017), un proyecto que nace a raíz de su propia participación en Una exposición coreografiada:

una experimentación acerca de lo que ocurre cuando las artes escénicas, activadas por seres humanos, salen de los contextos teatrales a los contextos expositivos museísticos.

¿Cómo afecta a la obra viva la temporalidad del museo?

¿Hasta qué punto se convierte en una mezcla de coreografía y reality show?

¿Cómo afecta al performer ese marco diseñado para objetos inanimados?

¿Cómo se comporta el público cuando se da ese choque de formatos? ¿Qué se espera de él? ¿Cuál es la convención a la que debe responder? ${ }^{5}$

${ }^{5}$ Extraído del texto de presentación de la obra en el Teatro Pradillo: https://www.teatropradillo.com/expografial. 


\section{El desencuentro con los lugares de actuación}

Volviendo al terreno teatral, la primera directora fichada por la nueva Volkbühne de Chris Dercon fue Susanne Kennedy. Su llegada a la compañía estuvo precedida por diversos premios y un creciente reconocimiento que la llevó hasta el Theatertreffen de Berlín en 2014, donde su trabajo causó polémica con propuestas como Purgatory in Ingolstadt (2013), con texto de Marieluise Fleißer, o la más reciente ¿Por qué enloqueció el Sr. R.? (Warum läuft Herr R. Amok?, 2014), inspirada en la película homónima de Rainer Werner Fassbinder y Michael Fengler (1969). Ambas fueron realizadas con el Teatro de Cámara de Munich, del que Kennedy fue directora invitada hasta su desembarco en Berlín. Las preguntas de Amalia Fernández acerca de los efectos que el espacio expositivo y hábitos del museo pueden tener en la recepción del trabajo del performer, y más concretamente en la del intérprete coreográfico, son trasladadas en el trabajo de Kennedy a la figura del actor y a la dramaturgia teatral. La directora holandesa transforma el teatro en un ámbito visual con una dimensión de fuerte carácter físico y emocional, que se articula, sin embargo, como un medio sumido en un proceso de atrofia terminal. Es a través de la reducción de la acción, gestualidad, expresividad e interacción, que se genera un espacio donde el público se ve interpelado - incluido y excluido a partes iguales - como si fuera un actor más atrapado en un entorno social que lo deja reducido al estatus de un autómata.

Siguiendo un determinado procedimiento escénico (sello de marca en los trabajos de Kennedy), la directora pone en escena un mundo de autómatas resignados con el medio en el que se mueven: un universo visual de figuras detenidas, vacías, incapaces de reaccionar. Los diálogos están previamente grabados, los actores no hablan nunca en escena aunque a través de su presencia, actitud y una mínima gesticulación (por ello también altamente expresiva) parecería que sí lo hacen. Incidiendo en este mecanismo de desconexión, la grabación de los textos ha sido realizada deliberadamente con gente no profesional y el rostro de los actores se cubre con una máscara de látex. En el caso de ¿Por qué enloqueció el Sr. R.?, la trama queda sintetizada en una selección de conversaciones anecdóticas sacadas de una película que sintoniza bien con esa dimensión aparentemente intrascendental del día a día. Fassbinder, sin embargo, es recorrido por pasiones reducidas a momentos puntuales de locura, como el que sucede al final de la obra. La impresión que queda del acontecimiento - y de la que se hizo eco la crítica (Rüdiger Schaper, Der Tagesspiegel) - es que se asemeja a un mundo de zombis, personajes intercambiables, seres anónimos que asisten mudos al espectáculo anodino de sus vidas, situados al mismo nivel que las plantas que decoran algunas de las escenas o de las marionetas expuestas en un escaparate. Los actores pasan a ser presencias extrañas en una trama que no dominan, con la mirada fija por la máscara y una actitud bobalicona. 
La pieza se desarrolla en una especie de sótano recubierto de madera que hace pensar en el interior de un sauna: un espacio geométrico sumamente reducido, que sirve al mismo tiempo de casa, oficina, bar, colegio y consultorio médico; una urna asfixiante, vacía y extraña cuya madera y las plantas que alberga dan una "impresión de naturaleza", pero en la que se percibe al mismo tiempo una artificialidad semejante a la de un laboratorio humano. Desde el patio de butacas, el ámbito de actuación se recorta como un cubo de luz alargado y encerrado en cristal. Cada escena está marcada por la subida y bajada de un telón, lo que impone una cadencia lenta y uniforme como si se tratara de planos inconexos de una misma película. No sólo los personajes parecen ignorar qué pintan en medio de la trama que los envuelve, sino que los propios espectadores comienzan a preguntarse cuál es el sentido de todo eso. En el desenlace, el Sr. R., en un momento de locura, termina matando a su mujer, su hijo y a una amiga de la familia, golpeándolos con una enorme maceta. Incapaces de cualquier tipo de expresión afectiva, la presión acumulada termina saliendo en un brote de violencia convertido en un momento cómico que el público agradece con risas, evidenciando también su alivio. La escena última es un extraño broche en el que aparecen los técnicos del Teatro de Cámara de Múnich improvisando un baile con "Let it grow" de Eric Clapton, una suerte de celebración por parte de los subalternos festejando la incapacidad de los actores profesionales para hacerse cargo del propio teatro que han creado.

En una conversación pública a raíz de la presentación de la obra en la Mostra Internacional de Teatro (MIT) de São Paulo en 2016, la directora explicaba que ella veía a los actores y espectadores del mismo lado de la escena, asistiendo impotentes a un drama - teatral- que los excluye, una maquinaria social y cultural que ejecuta sus funciones sin tener en cuenta a sus usuarios. Ante el desplazamiento del actor, todo el espacio es acaparado por dicho mecanismo, frente al que tanto el propio intérprete como el público parecen estar sometidos. La cualidad visual de la propuesta la acerca a una instalación con actores, lo que subraya la autonomía del espectáculo, que podría llegar a realizarse sin la presencia de espectadores o con un público que entrase y saliese de la sala a capricho.

Si Kennedy lleva al límite el artificio del teatro atrofiando deliberadamente la acción dramática, el artista libanés Rabih Mroué realiza una operación contraria, escapando del teatro por el lado de la no-ficción: su obra se convierte en una conferencia o exposición. La teatralidad no se difumina, sino que se hace recaer en el distanciamiento frente a los marcos de legitimación de la historia presentada, arrojando una interrogante sobre la veracidad de las imágenes y documentos que se utilizan. Trasladado al ámbito teatral, este mecanismo se convierte en una pregunta acerca del tipo de situación generada a través de la obra/conferencia. El público - que tanto en el caso de la obra de Kennedy como en ésta, esperaría encontrarse con alguna suerte de representación-, siente una sensación de desencuentro de la que tiene que hacerse cargo (un desencuentro que implica tanto al 
propio espacio como a la institución que lo enmarca). El desplazamiento de la representación, frecuentemente causante de actitudes de rechazo, suscita sin embargo, en este caso, un espacio y tiempo suspendidos, un momento abierto a la reflexión sobre los mecanismos que sostienen la construcción misma de los relatos (el del mártir, el de la guerra o el de la historia), y, por extensión, sobre la propia institución teatral y los modos de construir las representaciones. Pues el teatro, como dispositivo de representaciones, al mismo tiempo se superpone y es utilizado por otros tipos de dispositivos visuales y políticos, económicos y morales. Donde antes había una trama dramática, una historia, unos personajes y unas acciones para ser leídas, ahora hay un público preguntándose por la intención última de la presentación a la que asiste: ¿Teatro?, ¿conferencia?, ¿investigación artística?, ¿denuncia política?, ¿autobiografía?

El formato de conferencia al que recurre Mroué reiteradamente, muestra abiertamente los perfiles del desencuentro señalado. Lejos de la teatralidad dramática, es en cada caso el propio artista (en La revolución pixelada (2012), el propio director/actor; en Tan poco tiempo (2017), también él, acompañado de Lina Majdalanie; en Cabalgando nubes (2013), su hermano, Yasser Mroué) quien sostiene el cara a cara con el público. Presencias escénicamente neutras que remiten a algún tipo de ausencia, cuerpos sin apariencia de actores y en un registro que hace pensar más en una exposición académica que en una obra de teatro (como explicaba el mismo director en la misma edición del 2016 de la MIT, en la que se presentaron los trabajos aquí citados).

Aunque la idea de "conferencia performativa" es utilizada explícitamente sólo como subtítulo de La revolución pixelada (con la intención de evitar que la obra pudiera recibirse como un trabajo teatral), ese modo expositivo también característico de la obra de Kennedy, aunque con una elaboración teatral muy distinta, atraviesa toda la poética Mroué. La teatralidad de su trabajo radica, justa y paradójicamente, en ofrecerse negándose como teatro, sin dejar por ello de buscar presentarse en espacios teatrales dentro de centros culturales y festivales. Si el mismo producto fuera presentado, por ejemplo, en el aula de una universidad como parte de un congreso académico sobre historia política de Oriente Medio (el espacio que aparentemente le correspondería), su sentido variaría sustancialmente (tal como sucedería con la pieza de Rubén Ramos si se pusiera en un auditorio para conciertos). Es así la propia ausencia de teatralidad la que se hace sentir como otro tipo de teatralidad, articulándose en cada caso una relación de conflicto con los marcos culturales en los que operan estas obras. La impresión de cercanía con el público, sin la mediación de una estructura dramática, se convierte en un gesto formal que expresa una intención de encuentro e intercambio que, sin embargo, no llega a darse más allá del efecto estético producido por la obra.

Este juego de desplazamiento hacia lo real se refleja en todos los niveles; las imágenes, relatos o recuerdos - cuyo análisis detenido y cuidadosa exposición son el objeto de estos 
trabajos - expresan su cualidad escénica en tanto que son construcciones elaboradas desde un presente que se comparte con el público. Este último se (des)encuentra con un "actor" cuya interpretación consiste en una actitud de no-actuación mantenida desde el principio hasta el final, en un tono contenido y neutro al que contribuye la frontalidad con que se presenta. Desde un punto de vista de la pragmática, en comunicación, se despliega un tiempo entre paréntesis, suspendido, sostenido por un deseo de hacer visible una situación pública de discusión, reflexión y preguntas. Dichas preguntas quedan girando en la cabeza de los espectadores, la obra no intenta responderlas, sino hacerlas palpables tanto intelectualmente como a nivel sensible.

El teatro se convierte para Mroué en "una plataforma para compartir ideas y preguntas con otras personas. Es como un viaje en proceso que no tiene objetivo. [...] Es apenas el placer de pensar sobre el ser humano" ("Reconstruindo fragmentos", 41). Expuestas las interrogantes como resultado de minuciosos análisis acerca de cómo se producen las imágenes, cómo las recibimos y funcionan en la memoria, dichas preguntas no se limitan al plano material, sino que suscitan reflexiones sobre cuestiones básicas (identidad, guerra, violencia) y sobre el modo en que éstas se cuentan a través de las imágenes. El teatro de Mroué es una compleja maquinaria para pensar en voz alta y frente al público.

Tanto Kennedy como el artista libanés hacen un teatro que asume su propia incapacidad para llegar a algún tipo de respuesta o comunión con el público - más que en instantes particulares, como el cierre musical de la historia del Sr. R. o la identificación afectiva que se suscita con el actor de Cabalgando nubes, especialmente hacia el final de la interpretación musical-. Son poéticas que juegan con la potencia intelectual de la maquinaria teatral y se apoyan en presencias y acciones bien definidas, pero donde los cuerpos pierden su capacidad de acción en beneficio de una reflexión colectiva. El desencuentro intelectual se articula por medio de un espacio sensible desde el que se plantea una discusión sin resolver, que, en todo, caso queda pendiente para el público.

Este enfoque va un paso más allá en los proyectos del colectivo mexicano Teatro Ojo, en los que la delimitación del espacio entre actores y público se diluye porque escenario y platea pasan a ser funciones que se superponen en un mismo espacio (no ya un teatro, por lo general, sino cualquier otro entorno público con una memoria y una historia que rescatar). A partir de un proyecto de trabajo en el edificio Chihuahua en la plaza de Tlatelolco, S.R.E. Visitas guiadas (2007), Teatro Ojo descubre la riqueza teatral que esconden los espacios comunes y la posibilidad de arrojar sobre ellos una mirada escénica que saque a la luz estratos invisibles. A pesar de ello, en Lo que viene (2012) el grupo vuelve a un teatro, mas no para representar historias ajenas, sino para revisar las historias propias que le han ocurrido en otro tipo de espacios que no permiten el tipo de intercambio público propiciado por un teatro. 
El proceso creativo de este último montaje coincidió con los últimos meses del gobierno de Felipe Calderón, cuyo sexenio fue un periodo durante el cual México resintió un dramático aumento de la violencia por el narcotráfico. El teatro El Galeón, donde se realizó la obra, está dentro del complejo cultural del INBA (Instituto Nacional de Bellas Artes), situado a su vez a un lado del Memorial para las Víctimas de la Violencia, un polémico proyecto impulsado por el propio Calderón. La pregunta fue qué hacer, o mejor dicho, cómo utilizar una institución pública (un teatro del Estado pagado con el dinero de todos los ciudadanos) para hablar de lo que estaba pasando en ese momento en la vida pública de México. "Lo primero que pensamos - cuenta Héctor Bourges, miembro de Teatro Ojo - fue detenernos, interrumpir inercias, dar un tiempo y un lugar para mirarnos, recordarnos. Vaciar y descrear. Decidimos abrir - ocupar- el espacio escénico para hablar de eso que nos estaba pasando" ("Entrevista a Teatro Ojo", parr. 16). En Lo que viene, el teatro se abría al público ocho horas diarias, acoplándose más a los patrones de un museo o galería de arte que a los horarios normales de las funciones teatrales o a los usos institucionalizados de este tipo de espacios. Al quedar dispuesto como un lugar para recordar lo que otros ámbitos igualmente públicos han estado callando, el teatro comenzó a cumplir durante la temporada una función pública por excelencia. La gente encontraba al entrar una colección de diarios (los correspondientes a cada uno de los días del gobierno de Calderón), además de una serie de preguntas personales sobre las preocupaciones y sueños de cada "espectador", las cuales podían ser respondidas en voz alta a través de los micrófonos situados entre las notas de prensa. La obra iba construyendo así lo que ellos denominaron una "sismografía íntima", historias de los pequeños temblores que nos atraviesan todos los días.

Las instituciones tienen una función doble: se espera, por un lado, que sean capaces de resguardar un patrimonio (un pasado que hay que conservar), y, por el otro, que sirvan a la vida común del presente, en relación a la cual hay que situar dicho pasado. El desequilibrio entre estas fuerzas a favor del pasado las convierte en estructuras conservadoras que tienden a reafirmarse sobre sí mismas, sobre lo ya instituido (valores, formas, mitos y ritos ya construidos). Para recuperar lo que etimológicamente se espera de una institución, ¡su capacidad de instituir!, es necesario un trabajo previo de desinstitución y oposición a las inercias, o como decía Héctor Bourges: un tiempo para parar y mirar alrededor, un tiempo para preguntarnos. Ocupar de una forma crítica los espacios de producción, ocupar los teatros, centros culturales, auditorios y salas de exposiciones, implica hacer un uso disfuncional de esos espacios, utilizarlos - al tiempo que se inutilizan para los usos ya previstoscon el objetivo de abrir otras formas de circulación del capital, del arte y el conocimiento; de las actitudes y los afectos.

Precisamente eso es lo que hacen las obras que hasta aquí hemos venido revisando: proponen distintas formas de ocupar esos espacios de representación llamados teatros, 
con el fin de provocar reflexiones acerca de los modos de desinstituirlos e instituirlos con usos renovados. Tales estrategias son capaces de afinar la conciencia del tipo de espacio al que asistimos cuando participamos de un evento escénico, así como de las normas implicadas en ellos, devolviendo a estos ámbitos la posibilidad de convertirse en lugares de verdadero uso público. Sólo así logran admitirse otros modos, generando tiempos de suspensión y desencuentro que abran la posibilidad de repensar lo que estamos haciendo en estos sistemas de representaciones.

\section{El teatro como forma de descolonización: lugares de habla / lugares de acción}

La edición de la MIT en la que coincidieron estos trabajos de Susanne Kennedy y Rabih Mroué, tenía como ejes transversales los lugares del habla y la descolonización, dos temas que responden también al trabajo de Teatro Ojo o a la propuesta de Rubén Ramos. Aunque son asuntos distintos, no resulta difícil encontrar la relación entre ambos. Los lugares de legitimación de la palabra se convierten fácilmente en mecanismos de poder que históricamente han contribuido a sostener los procesos de colonización. No en vano, el teatro es una institución que desde sus orígenes modernos ha funcionado como un fiel aliado en la construcción de las identidades nacionales y de los modos de colonización cultural que impulsaron los procesos de expansión de naciones poderosas. A lo largo del siglo xx, este dispositivo de construcción de representaciones ha ido perdiendo las señas de identidad locales para hacerse más abstracto y más fácilmente exportable, como ocurrió también con los museos.

La reinvención de los lugares de actuación que hemos ejemplificado mediante las obras descritas, va unida a un proceso de reflexión acerca de las formas de construcción de los relatos y sus potencias críticas. No es suficiente con hacer como si no se actuara, se necesita tomar conciencia de los elementos de poder que sostienen a un dispositivo de creación (espacio cultural o institución artística), para plantear de forma eficaz la mejor estrategia de ocupación - para interrumpir sus inercias y abrir tiempos de suspensión, desde los que sería posible repensar otras posibilidades al ocupar dichos espacios en relación con el pasado que ellos inscriben-.

La misión en fragmentos: 12 escenas de descolonización en legítima defensa, dirigida por Eugênio Lima, fue una de las producciones del propio MIT en la misma edición de 2016. Consistió en una adaptación del texto inacabado La misión de Heiner Müller, interpretado por un colectivo numeroso de intérpretes negros amateurs que se habían juntado especialmente para este proyecto: Legítima Defensa. La propuesta retoma la discusión so- 
bre la posibilidad de la revolución tal y como se desarrolla en el texto de Müller (a partir de la experiencia jamaiquina), para cruzarla con el imaginario del quilombo en tanto que espacio de baile, resistencia y organización desarrollado en la cultura brasileña como estrategia de defensa por parte de los esclavos.

A pesar de la potencia física y colectiva de la obra, expresada por medio de bailes y cantos corales, su desarrollo formal termina sometiéndose al texto dramático y a la necesidad de representarlo. Hay un momento hacia el final en el que los actores invaden el espacio de las butacas para cuestionar la legitimidad del poder blanco, de la historia e, indirectamente, del tipo de teatro que se está haciendo, pero la acción queda como un tímido intento, dentro de una propuesta dramática que no consigue darle a la cualidad física y memoria colectiva de los intérpretes una dimensión crítica eficaz. Estos últimos no llegan a habitar el imponente espacio del auditorio Niemeyer en el que trabajan, a apropiarse de él imponiendo unas nuevas reglas de construcción u otras formas de estar y presentarse frente al público. La misión queda en un intento más de oposición a una historia de poder cuya materialización más inmediata, en ese momento, es la propia historia del teatro como legitimación de unas formas predeterminadas de habla y actuación.

Sin embargo, al final de la obra se eleva la pared del fondo del escenario, dejando ver el parque de Ibirapuera con sus árboles y zonas verdes en medio de la noche. Por esa enorme ventana mágica que conecta con la realidad exterior, comienza a entrar una multitud de gente, todos negros, que invaden el escenario para unirse a los intérpretes en un estallido de fiesta. Ese momento impresionante hace pensar en las posibilidades de un teatro cuyo punto de partida sea la suspensión de las propias reglas del teatro, un teatro que se apoye en la teatralidad en sentido amplio - no en la tradición dramática ni en las formas escénicas ya constituidas, sino en las personas y sus lugares, en la memoria y sus relatos-.

La pregunta que arroja esta puesta de La misión es cómo hacer creíble tal quilombo teatralmente, cómo darle realidad escénica a ese acto de ocupación, cómo sostenerlo en un espacio de la magnitud del auditorio Niemeyer (un tipo de construcción de los años 50 característico del arquitecto brasileño). La abstracción del espacio de la que ha dado buena muestra la arquitectura moderna, ha ido en paralelo al crecimiento de su poder simbólico, un poder que se ha proyectado también a las instituciones dedicadas a la cultura. Dicho proceso de abstracción, como ya estudió Henri Lefebvre en los años sesenta, es el que sostiene la lógica económica que a menudo regula la administración de los espacios públicos y, de forma más general, de lo público.

"Lo público" deja de ser un bien común cuya lógica esté en función del uso cotidiano y su apropiación por parte de quienes lo transitan, para convertirse en una abstracción, resultado de una calculada operación de medidas políticas e intereses financieros que dejan fuera de juego a sus usuarios. Estos pasan a ser actores de una obra que no han escrito, tal 
como terminaba ocurriendo en La misión; figurantes de una maqueta diseñada a una escala que les supera. El resultado sería distinto si la obra se realizara en otro tipo de espacios - no teatrales - y ante un público que no fuera el característico de un festival internacional de teatro, como la MIT. En ámbitos marginales y ante comunidades no familiarizadas con la institución teatral, que en principio es el destino final de este proyecto, el sostenimiento dramático de la fábula de Müller podría acaso ser entendido de otro modo.

Convertidos en objeto de especulación, calles, plazas y parques, así como teatros y otros edificios patrimoniales, suelen pensarse hoy en día a partir de su valor de cambio (ya se trate de capital material o inmaterial) antes que de su valor de uso. ¿No se consideran los teatros espacios simbólicos por excelencia, valorados más por lo que tienen de promesa cultural que por el uso que se hace de ellos? ¿En qué medida los teatros oficiales, convertidos a menudo en construcciones históricas con un pasado y una carga cultural bien identificados, continúan funcionando como formas de colonización cultural? ¿De qué capital simbólico hace ostentación la imponente geometría del auditorio Niemeyer y de qué tipo de capital humano nos está hablando La misión? ¿No sería más sensato renunciar a ese fabuloso escenario - o en todo caso desviar su uso, clausurar la escena, plantear la obra en los alrededores (por fuera del edificio) - para conquistar momentáneamente, hacia el final de la obra, ese núcleo de poder sin rostro que es la escena del capital financiero y blanco, tan estrechamente vinculada a esta arquitectura?

Aunque esta última pregunta podría radicalizarse aún más para sopesar si este tipo de espacios teatrales son realmente los que queremos conquistar, o si los espacios verdaderos de actuación están más bien en otros lugares de la ciudad. ¿Siguen siendo los teatros históricos y espacios institucionales de la cultura, lugares válidos para pensar y situarse en el mundo? La respuesta debería ser afirmativa, puesto que son estructuras sostenidas por el dinero público que deben cumplir por lo tanto una función pública; pero esta respuesta está condicionada a la necesidad de reflexionar sobre cuál es la función pública que debe cumplir hoy el teatro. A todas estas preguntas tratan de responder proyectos de programación en teatros y centros de arte como los apuntados al comienzo de este artículo.

\section{Conclusión}

El teatro es un lugar de habla cuyo valor simbólico le confiere cierta fuerza de legitimación, donde este hablar es además - y al mismo tiempo - una forma de acción, un modo de actuar y situarse en público, una posible vía para intervenir en un espacio social e institucional. Trastocar los lugares de habla implica transformar las formas de actuación y el lugar de los actores, mediante desplazamientos que ofrecen la posibilidad de generar espacios de 
suspensión desde los cuales es posible recuperar el pasado (artístico, musical, teatral y/o político) de modo que nos interrogue y nos mueva. De eso nos hablan las obras revisadas hasta aquí.

En Amateur se utilizaba el teatro para denunciar la rigidez y elitismo de los modos que la música clásica, como institución, había fijado para relacionarse con ella. Al mismo tiempo que se desarrollaba dicha reflexión, la puesta en escena se situaba en el escenario teatral de una forma inédita, reivindicando la figura del aficionado. El acto de tocar el piano se convertía en un gesto y una acción; un gesto que se dibuja frente al horizonte institucional de la música y una práctica sostenida escénicamente. Hacer y decir se solapaban, pues, como dos caras de una misma acción.

En las obras revisadas de Kennedy, Mroué y Teatro Ojo, de manera semejante, el teatro se transformaba en un espacio de reflexión colectiva con una cualidad expositiva que acercaba estos trabajos al mundo de las artes visuales, sin que ninguno de ellos renunciara a una teatralidad propia y disruptiva. La representación no constituía una finalidad para ninguno de ellos, sino el intento de usar y proyectar el espacio de actuación, y con ello la posibilidad de poner a la acción en relación con el público, generando un distanciamiento crítico con respecto al entorno cultural que organiza tales espacios. En los trabajos de Ramos y Mroué, es la apelación directa al público la que despliega dicho ámbito de reflexión conjunta. En la obra de Kennedy, por su parte, es la avería de la representación la que la convierte en un horizonte de contemplación que se extiende a lo largo de un tiempo que parece no avanzar, y que se proyecta en el público en forma de preguntas sobre la posibilidad misma de la acción. Pero es en el proyecto de Teatro Ojo donde esta apertura de un espacio de encuentro y desencuentro con nosotros mismos a través del pasado, se construye de forma más horizontal y abierta. Aquí ya no hay más actor que el propio público, enfrentado con su propia memoria, imágenes y representaciones.

En Una misión, contrastantemente, la construcción de la representación sigue estando, en primer y último lugar, como un plano sin resolver, al igual que la propia pregunta por la revolución que se plantea. La puesta en escena no consigue abrir una distancia frente a su horizonte de representación, el cual hace sentir sus reglas con la legitimidad que parece conferirle la potencia espacial del tipo de edificio en el que el montaje tuvo lugar, imponiendo unos modos históricos de enunciación ya identificados por la tradición teatral. Son definitivamente las propuestas de Ramos, Mroué y Teatro Ojo las que, de forma más clara, responden al deseo de extradisciplinariedad al que se refería Holmes.

Por otra parte, y al igual que muchas otras propuestas recientes para llevar la performance o la danza al museo, el trabajo de Kennedy corre el riesgo de quedar en un ejercicio de autorreflexión estética, tornándose un producto artístico demasiado asimilable en los espacios donde pretendía insertarse de manera innovadora. El caso de Una misión es dis- 
tinto en tanto no tiene una voluntad autorreflexiva, pero, reiterando, no consigue tampoco romper el marco de la obra dramática para proponer un nuevo lugar de encuentro y desencuentro susceptible de permitirnos repensar con cierta eficacia la posibilidad, si no ya de la revolución, al menos de la acción a través de la escena.

Aunque el único de los trabajos aquí citados que recupera explícitamente a la figura del aficionado es Amateur, todos ellos incorporan de forma diversa ese lugar como umbral de desestabilización y renovación de los usos institucionalizados del teatro y, en general, de las artes. Kennedy saca a los técnicos al final de la obra para hacer una coreografía casera; Mroué invita a su hermano, aún sin presentarlo como tal, para compartir con el público su propia memoria personal; Legítima Defensa es un grupo integrado por aficionados, aunque resulte evidente que en su entendimiento de la actuación miran hacia un horizonte de profesionalización teatral. Pero es nuevamente el trabajo de Teatro Ojo, que pone todo el tiempo y espacio del escenario a completa disposición de los espectadores, el que más radicalmente se ocupa de señalar la condición de aficionados que tenemos todos en casi todos los ámbitos de la vida, así como la necesidad de retomar ese ámbito indiferenciado que es el espacio común, como lugar de posibilidad para repensar la situación en la que nos encontramos.

Entender al teatro como un lugar de encuentro es uno de los mitos a los que suele recurrirse para imbuir de un sentido público y abierto cualquier evento cultural que no se quiera plantear de forma jerarquizada o vertical. Es en esta perspectiva donde han confluido, por cierto, el teatro y las artes visuales. La idea es que la actividad y - en su caso- la obra generen un ámbito de relación y transformación del entorno. El discurso del encuentro remite a unos orígenes desde los que se supone posible volver a pensar un rito artístico como lo es el teatro - que al igual que cualquier otro acto cultural está en permanente riesgo de perder su capacidad crítica e instituyente- para convertirse en un producto de consumo más - como argumentaba Lygia Clark- Pero la modernidad no nace de un mito, sino de la ruptura de mitos, o en palabras de Jean-Luc Nancy, de la suspensión del mito o de la representación y las identidades (La communauté désoeuvrée). Así pues, convocar al desencuentro es también necesario en la medida en que éste es la herramienta que permite sostener un estadio colectivo de suspensión, abriéndolo a otras formas prácticas de discusión del pasado. ¡No hay encuentro entre los individuos sin la posibilidad de desencuentro con las propias instituciones que custodian el pasado común de prácticas, lenguajes y valores! Solamente de este umbral de inestabilidades respecto al pasado surge la posibilidad de que las instituciones recuperen su capacidad instituyente, más allá de su función de administrar lo ya instituido. 


\section{Bibliografía}

Bishop, Claire. Radical Museology, or What's "Contemporary" in Museums of Contemporary Art? Londres: Koenig Books, 2013.

Buchloh, Benjamin. "El arte conceptual de 1962 a 1969: de la estética de la administración a la crítica de las instituciones". Formalismo e historicidad. Modelos y métodos en el arte del siglo XX. Trads. Carolina del Olmo y César Renduelles. Madrid: Akal, 2004, pp. 167-200.

Cartografías. MITsp. Revista de Artes Cênicas, núm. 4, 2017.

CiudaDistrito. "Programación cultural del Ayuntamiento de Madrid". CiudaDistrito. Ayuntamiento de Madrid, en línea. Consultado el 15 de noviembre de 2017.

Copeland, Mathieu. Coreografiar exposiciones. Madrid: Centro de Artes Dos de Mayo, 2017.

Dewey, John. El arte como experiencia. Trad., ed. y pról. Jordi Claramonte. Barcelona: Paidós, 2008.

Fernández, Amalia y Anto Rodríguez. Expografía. 2017-2018. Teatro Pradillo, Madrid, 2017.

Holmes, Brian. "Investigaciones extradisciplinares. Hacia una nueva crítica de las instituciones". Producción cultural y prácticas instituyentes. Líneas de ruptura en la crítica institucional, Boris Buden, et al. Madrid: Traficantes de sueños, 2008, pp. 203-215.

Kennedy, Susanne. Warum läuft Herr R. Amok?, Rainer Werner Fassbinder y Michael Fengler. 2014-2015. Münchener Kammerspiele, München, 2014.

Kunst, Bojana. Artist at Work. Proximity between Art and Capitalism. Londres y Nueva York: Zero Books, 2015.

Lefebvre, Henri. La producción del espacio. Trad. Emilio Martínez Gutiérrez. Madrid: Capitán Swing, 2013.

Lima, Eugênio. A missão em fragmentos: 12 cenas de descolonição em legítima defesa, Heiner Müller / Claudia Shapira. Legítima Defensa. 2016-2017. Mostra Internacional de Teatro, Auditório Ibirapuera - Oscar Niemeyer, São Paulo, 2017.

Mroué, Rabih. "Reconstruindo fragmentos: Rabih Mroué em Cavalgando nuvens". Entrevista con Cis Bierinickx. Cartografías. MITsp. Revista de Artes Cênicas, núm. 4, 2017, pp. 38-41.

Mroué, Rabih. Riding on a Cloud. 2016-2017. Münchner Kammerspiele, München, 2017.

Mroué, Rabih. Such Little Time. 2016-2017. Theater am Ufer, Berlin, 2016.

Mroué, Rabih. Pixelated Revolution. 2012. Documenta 13, Kassel, 2012.

Nancy, Jean-Luc. La communauté désoeuvrée. París: Christian Bourgois, 1983.

Ramos, Rubén. Goldberg Amateur. 2017-2018. Festival tNT, Piano Bar Reina Victòria, Terrasa, Barcelona, 2017. 
Ramos, Rubén. Gibbons Amateur. 2016-2017. Espacio Nyam Nyam, Barcelona, 2016.

Real Academia Española. "Institución". Diccionario de la lengua española. En línea. Consultado el 15 de noviembre de 2017.

Roznik, Suely. "La memoria del cuerpo contamina el museo". Instituto Europeo para Políticas Culturales Progresistas, núm. 1, 2007, en línea. Consultado el 21 de enero de 2018.

Schaper, Rüdiger. “Zeit der Zombies”. Der Tagesspiegel, 5 marzo de 2015, en línea. Consultado el 13 de julio de 2017.

Teatro Ojo. "Entrevista a Teatro Ojo". Entrevista con Gabriel Yépez. Archivo Virtual de Artes Escénicas, 26 de junio de 2016, en línea. Consultado el 21 de enero de 2018.

Teatro Ojo. Lo que viene, Héctor Bourges. Teatro Ojo. 2012-2013. Teatro El Galéon, México, 2012.

Teatro Ojo. S.R.E. Visitas guiadas, Héctor Bourges. Teatro Ojo. 2007-2008. Universidad Nacional Autónoma de México, Secretaría de Relaciones Internacionales, México, 2007. 